\title{
Analysis on the Innovation and Development of College English Education in the New Era
}

\author{
Xiaojin $\mathrm{Wu}$ \\ Feixian Campus Linyi University \\ myshyl216@163.Com
}

Keywords: College english in the new era innovation and development

\begin{abstract}
With the development of economic globalization, the international economic integration of the contemporary, English I, the most widely used language in the world, whose as position and value are more and more important. As a main function of communication language, English plays an important role in our daily life, study and work. Under this new background, the requires raised by English also is changing that we not only get good exam achievement, more words , the grammar, but also can communicate, namely, listening and saying. This also means that the educational institutions that teach us to learn English, especially the colleges and universities are put forward new challenges, but, there are many flaws in teaching students English which makes us unable to meet the demands of our society and unable to adapt to the requirement of internationalization and globalization.so , This article has analyzed the current college English teaching mode, found out the loopholes, and put forward the corresponding improvement measures.
\end{abstract}

\section{Introduction}

With the rapid development of China's economy, China's strength, China whose international status has also been booming, in the world, occupies more and more right to talk, is also increasingly close contact with the world. Nowadays, More and more Joint ventures emerging, to better satisfy the require communicating with foreigners, studying English well and communicating in English is an essential ability for their job and promotion But nowadays, there are still some problems in College English education, which is not fully play the role of College English education, which is not good enough to meet the needs of students and society.so In order to improve the students' personal competitiveness and the competitiveness of Chinese enterprises in the world, it is urgent to speed up the innovation and reform of College English education and make it more suitable for the students to adapt to the society.

\section{The Importance of English}

It is necessary to know the importance of English for author before discussing the English education problem. Only fully aware of the role of English in today's society, fully aware of the importance of English, people will pay more attention to English and spend more time on English. Here, it's not only said that the University, and the students in Colleges and Universities. Universities should fully realize the importance of English, and then reform the existing methods of English education, give full play to the functions of the University. Students should be more aware of the importance of English, in the school period, should take full advantage of the resources provided by the school to learn English well, rather than feel so regret having a bad learning in English after the inauguration. The author will list a few points, to illustrate why we should learn English, why should learn English.

Firstly, it's more people using English. English is one of the main international languages and also the most widely used language in the world. According to the statistics of 1986, Nearly 400 million people is native English speakers, almost one in every ten people speaking English. People in Britain, the United States, Canada, Australia, New Zealand, etc all speak English. There are about 20 countries a total of about 800 million people, In the world taking English as the official language or second language .in other words, Almost one in every five people in the world knows 
English to a certain extent. If adding the number of primary and secondary school students in the world to learn English, the English speaking people will be more.

Secondly, range of application in English is wide. English is widely used. More $70 \%$ emails and it's address are written in English in the world.60\% TV shows in the world is going in English. The vast majority of the world's information is published in English. The vast majority of international conferences take English as the first language, and it is also one of the official working languages of the United Nations. In a word, In the international politics, military, economy, science and technology, culture, trade, transportation and other fields, English is an important tool of communication.

English is the trend of the times, The era of globalization has come, consulting transfer, cultural exchanges, if want to survive in this international arena, you must have the ability to communicate in oral English. Learning English is not just for the meet international demand, but also for the expansion of our own knowledge. In recent decades, China has happened the earth shaking changes, all aspects of the development being fast, but, in the meantime, there is no doubt that we are still behind the West in many technical aspects. To develop, to progress, in a relatively short period of time to master a variety of technologies, we cannot rely on their own research, must learn advanced technology in developed countries. And the necessary prerequisite for learning is to master the world's common language - English.

Therefore, Colleges and universities should implement the reform of English education, to ensure that the teaching of the students' English proficiency, to meet the requirements of this era of the community

\section{Problems in College English Education at Present}

At present, China's English education still retains the traditional English teaching concept which is to teach the spelling and memory, grammar structure analysis, etc. Only paying attention to the examination results, but ignoring the students in the practical application of English training. As for the students, many students simply take English as a subject and only learn to get good score, not fully aware of the English. there is no clear understanding to under the background of today's English which will have a huge impact for the future work and life. These problems and their causes can be attributed to the following points

English Teaching Methods are too Conservative. Now the English education is still examination oriented education, that is, to take the syllabus as the center of the curriculum teaching, taking the basic grammar as a teaching focus, but ignoring the English language culture and the nature of English teaching and the importance of English as the core competence of employment. China's examination oriented education concept deeply rooted, senior high school entrance examination, college entrance examination make students, parents even society concerned about exam performance. Colleges and universities, for fame, having a good reputation in the community, naturally, will attach great importance to the students' test scores, which led to the results of the English teaching method is too conservative. It's a big problem that dare to innovate, do not want to innovate and cannot innovate

The Problems of Teachers. In present college English class, some teachers just teach in order to complete the teaching task. Efforts to complete the task of teaching being understandable, but if to complete the teaching task and ignore the learning situation, it don't deserve the teacher's rigid teaching ways make classes boring which lead to gradually spend the enthusiasm and interest in learning English, finally cause students present at class just for check work attendance. Such unilateral lectures, unilateral lectures, not only reduce the efficiency of the classroom, but also reduce the frequency of interaction between teachers and students, and often do not get the desired results.

The Problem of Students. Just mentioning the teachers, it's turn to students. After all , students are the subject of study. Wanting to learn English well and use it smoothly not only need the effort of the teachers and the university, but also student's own struggle. many students don't realize the 
importance of English then ignore it and hate to learn . More undergraduates are only to obtain a diploma and a Certificate IV in English, and don't accept and identity English at all. More students, because lazy or a variety of reasons, always despise the importance of English, thinking that they will not use English and can also be life to ignore the learning of English. when they are in jobs ,they will regret Why they didn't have a good study, hating to let the time back and learn English again .

\section{Innovative Strategies of College English Education}

Firstly, it is the upward force of the mandatory provisions. The Ministry of education, as a straight branch of all colleges and universities, should have a clear regulation to encourage all colleges and universities to make bold and innovative English teaching methods. At the same time also introduced some available for reference of various colleges English teaching model, the most important is to eliminate various colleges and universities Koko to exam outline for the center of the concept, to promote the all-round talents cultivation, attaches great importance to the comprehensive quality education This requires the Ministry of education to draw on foreign teaching experience and combined with the actual situation in the country to adjust the examination form. In addition, it is necessary to change the pattern, who is the center of the pattern in College English teaching, quickly and well changing the teacher to the students as the center. To give full play to the main role of students in the classroom, on the one hand, it's to stimulate interest in learning, on the other hand, to strengthen the students' oral English.

Secondly, it's the innovation in the school

Teachers Should Have the Courage to Reform the Teaching Content and Objectives. College English teaching on the basis of existing English language knowledge and language skills, should also learn strategies and cross cultural communicative knowledge adding the essence of the language learning to the classroom, really taking the English as a communication tool and a cultural transmission broadcast, an art appreciation. The reform of learning strategy is to improve students' learning ability, to enhance their autonomous learning ability, so that students have their own learning methods, after having their own learning methods, Students will be on the road to innovation in the future.

The innovation of teaching aims is to change the original English grammar as the goal of learning to cultivate students' autonomous learning and intercultural communication ability. On the one hand, it can improve students' autonomous learning ability, and it is convenient for students to realize the goal of lifelong learning in the future work and life. on the other hand, it's to strengthen students' intercultural communicative competence and broaden their horizons, to provide themselves with an opportunity to understand a new culture, new thinking and new field of art.

Schools Innovate Curriculum. The current English curriculum mainly has three courses, the intensive and extensive reading and listening which is too simple. Now, In order to cultivate the talents suitable for the development of the society, all colleges and universities should set up different English teaching methods according to the different majors. For example in civil engineering, social management of public utilities, financial management professional students, according to the subject characteristics, strengthening professional English teaching. It can not only improve the students' employment competitiveness, but also for students further study studies play under thick and sturdy foundation of language. What's more, changing the nature of the curriculum in English, it is to take a combination of compulsory and elective, so that students in accordance with their own needs free choice of learning courses. Of course this creativity requires schools to offer unique courses, such as English appreciation course, foreign cultural appreciation class such knowledge and art and inclusive curriculum. Once the school with the characteristics of the teaching, is conducive to enhance the quality of the school's enrollment, conducive to the improvement of the quality of the students, improve the rate of employment of students, improve the social prestige of the school which is a virtuous cycle.

Innovation of Teaching Mode and Means. In this age of science and technology, digital, high technology has been integrated into every corner of life and work. So the teaching mode is no 
exception, in general, the innovation of teaching mode can be summarized as three aspects of personalization, networking, and three-dimensional innovation.

In these three aspects, should pay special attention to personalized innovation. Personalization is required in the teaching syllabus and curriculum on the basis of the training of general ability, higher capacity and higher ability of students. Once breaking highlight the characteristics, it will inspire students' interest in learning, so as to improve students' overall English level, but also cultivate the students' individual English learning content, let the students have their own unique characteristics of the English level.

Network implementation requires the school to pay a certain cost to improve the school's hardware facilities, further integration of the resources inside the school, to build a high-tech teaching platform. For example, multimedia teaching has enriched the basis of English teaching and improved the teaching methods of English. When using multimedia teaching, first of all requiring English teachers using multimedia technology to make the PPT, flash, traditional blackboard teaching changed into pictures, music, videos, a model of teaching, so as to stimulate students' multiple sensory, deepen students' understanding and memory of classroom knowledge. The most important is that teachers use the Internet to enrich the knowledge of the classroom, and audio and video applications to further enhance the students' English listening.

Three dimensional can be understood as a multi-dimensional as to avoid a single classroom teaching combining the internal and external. After school time, organizing students to participate in some social practice can make students really understand the importance of English, so as to improve the students' attention to English. At the same time, improve the utilization of school multimedia equipment, such as campus radio, campus micro-blog platform, network courses, etc. Teaching mode of Network and three-dimensional combination, through the network platform can enhance the exchange between students, which is conducive to the cultivation of students' spirit of exploration and innovation.

Innovation of Ideas. The status of teachers in the teaching process is not negligible, so a teachers guiding the innovation should first change their own view of English teaching, changing the teaching focus from the traditional transformation to develop their oral and communicative ability. Teachers can learn from foreign experience, such as cooperative teaching methods, deepen the teaching concept and improve the innovation level of English. firstly, teachers should understand the importance of innovation in English teaching so to improve their teaching methods and increase open teaching mode. then, The school can employ foreign teachers, which is convenient for teachers to learn from others, but also provides students with the opportunity to learn local English.

Lastly, it's students own attention and effort in English. Colleges and universities should strengthen the publicity, so that students can correctly understand the importance of English, after understanding of the English language influence on their later life, so as to learn English independently. Students themselves should be more efforts to make full use of the resources provided by the school to enrich themselves, not to waste to survive, so that they will not be regret not to learn English well.

\section{Conclusions}

Nowadays there being a lot of places for College English reform, colleges and universities should actively respond to the current learning situation in a timely manner to make corresponding changes and innovation, helping students grasp English to ensure that students into the community can be a better integration into the community, serve the community, contribute to the development of China's own strength, so that China has become more beautiful.

\section{References}

[1] Ling Yun. In the new period discussion on the innovation and development of College English education [J]. English Square), 2013, (11): 115-115. 
[2] Liu Wenna. The innovation and development of English education in Universities in the new period [J]. Northern Literature (Late), 2012, (4): 174- 174.

[3] Qiu Shuang. The research on College English education innovation [J]. English (published in late 2014, square), (3): 118-119. 